\title{
Percepção de riscos na
} internacionalização do setor alimentício

\author{
Gabrielle Ribeiro Rodrigues da Silva, Simone Cristina Ramos ${ }^{1}$, \\ Gustavo Abib e Karina De Déa Roglio \\ Universidade Federal do Paraná, UFPR, Curitiba, PR, Brasil
}

\section{DETALHES DO ARTIGO}

\section{Histórico do Artigo:}

Recebido: 18 de maio de 2017

Revisado: 11 de setembro de 2017

Revisado: 15 de dezembro de 2017

Aceito: 22 de fevereiro de 2018

Disponível online em: 01 de maio de 2018

Sistema de revisão "Double blind review"

\section{Editor Científico}

Ilan Avrichir

\section{Palavras-chaves:}

Risco

Internacionalização

Teoria Comportamental de Internacionalização

Percepção de Riscos

\begin{abstract}
RESUMO
O processo de internacionalização de organizações brasileiras está em ascensão gradativa. Em atividades internacionais os riscos, já presentes no mercado doméstico, são incrementados em função das características peculiares do mercado em que se deseja inserir um produto ou serviço. Ainda que em termos ideais seja possível afirmar que é necessário analisar todos os riscos que podem acometer a organização, a racionalidade limitada não permite ao gestor da organização processar todas as informações, seja por falta de conhecimento ou capacidade analítica. Sendo assim, o objetivo proposto para este artigo é compreender quais são os riscos percebidos associados ao processo de internacionalização em empresas do setor alimentício. A abordagem condutora da investigação é estudo de casos múltiplos, alicerçados em entrevistas semiestruturadas, observação e análise documental. Os resultados indicam diversidades no conceito de riscos entre as organizações; diferenças entre os tipos de riscos considerados e influência desta percepção sobre as práticas organizacionais. Como contribuição é possível apontar a construção de evidências coerentes com a teoria comportamental de internacionalização, onde mais do que um processo comercial e econômico, tal ação constitui-se como uma construção complexa da realidade, influenciada pela percepção e atitudes dos gestores envolvidos.
\end{abstract}

(C) 2018 Internext | ESPM. Todos os direitos reservados!

\section{INTRODUÇÃO}

O interesse pelo tema internacionalização vem crescendo ao longo dos anos, pois o fenômeno é um desafio para governos, instituições e organizações (Guedes; Faria, 2010). Em parte o desafio advém das diferenças entre o contexto nacional, como cultura, idioma, legislação e especificidade dos cenários político e econômico do país alvo da operação de internacionalização (Milliman; Glinow; Nathan, 1991). Outro elemento que incrementa a complexidade em operações internacionais é o risco, pois aqueles existentes em âmbito nacional somamse outros como riscos de guerras, epidemias, financeiros e políticos internacionais (Welch; Welch, 2004).

A internacionalização de empresas brasileiras vem crescendo, fato que ressalta a necessidade de estudos acerca da temática. O Brasil, segundo os dados do Ministério do Desenvolvimento, Indústria e Comércio Exterior (2017), teve um incremento de $12 \%$ na quantidade de empresas exportadoras em 2016, frente aos dados do ano anterior, totalizando 19.419 organizações. Outro indício de intensificação da internacionalização é o aumento do investimento direto no exterior, que triplicou no período de 1995 à 2010, totalizando uma movimentação de 181 bilhões de dólares em 2010 (Rocha, 2014). Também no Paraná, sede das organizações estudadas, o fenômeno é significativo. O Estado teve como valor exportado, em 2015, US\$ 14,9 bilhões, sendo o terceiro maior exportador no agronegócio e liderando a exportação de carne de frango (MDIC, 2017).

Embora o número de organizações que

\footnotetext{
${ }^{1}$ Contato do autor E-mail: simone.crisr@gmail.com
} 
internacionalizam seja expressivo no território nacional, ainda há pouco entendimento na literatura da área de internacionalização sobre como os riscos afetam o curso da internacionalização (Liesch; Welch; Buckley, 2011). O trabalho revisional de Polo, Peixe e Galegale (2013) aponta, a partir da análise da produção internacional sobre riscos entre 2000 e 2012, que os estudos são focados em riscos muito específicos e majoritariamente financeiros. A análise da produção nacional empreendida por Botinha et al. (2012) indica que as investigações sobre riscos enfatizam questões ambientais, crédito, investimentos e negócios. Frente a isto é possível afirmar que estudos sobre os riscos em processos de internacionalização contribuirão para a ampliação dos conhecimentos neste campo, visto que somente um estudo sobre risco e internacionalização foi publicado na revista brasileira de negócios internacionais (Internext) no interstício de 1999 a 2013 e que se aponta como necessidade a elaboração de estudos que envolvem estas duas temáticas (Ribeiro, 2014).

O risco é um fator relevante em vários níveis de atividade internacional, sobretudo em situações nas quais as empresas ingressam em novos mercados ou mudam sua estratégia (Liesch; Welch; Buckley, 2011). Embora haja estudos identificando os tipos riscos no processo de internacionalização, pouco entendimento é associado aos riscos efetivamente considerados pelos gestores (Liesch; Welch; Buckley, 2011). Para os autores, resta inexplorada a investigação dos constructos utilizados pelos gestores para analisar e ponderar o risco em processos de internacionalização.

Frente a este cenário o objetivo nesta produção acadêmica é compreender quais são os riscos percebidos associados ao processo de internacionalização em empresas do setor alimentício. Justificativas teóricas e práticas podem ser associadas a este objetivo. Do ponto de vista teórico o conhecimento produzido refere-se a um gap existente na literatura sobre internacionalização, e pode auxiliar no desenvolvimento do campo. Como justificativa prática pode ser apontada a possibilidade de utilizar o conhecimento construído no aprimoramento dos processos educacionais de gestores e diretamente pelas organizações, o que contribuiria para o aprimoramento do processo de gestão de riscos.

Para consecução deste objetivo este artigo é composto de mais quatro seções além desta introdução. A próxima seção é o referencial, que contém a argumentação teórica presente na investigação. O próximo tópico é a metodologia, que contém a caracterização da investigação e a descrição das práticas materiais do pesquisador. Os dois últimos segmentos são a descrição e análise dos resultados e conclusões.

\section{REFERENCIAL TEÓRICO}

São apresentadas as revisões sobre correntes de estudo sobre internacionalização e os riscos e sua percepção em processos de internacionalização. Esse arcabouço apresentado é necessário a fundamentação e compreensão do presente estudo.

\subsection{Correntes de estudo sobre internacionalização}

O risco é uma característica proeminente das organizações contemporâneas e seus ambientes, tornando-se um tópico tão importante quanto à riqueza organizacional (Tsoukas, 1999), aflorando a necessidade do envolvimento dos gestores na gestão de riscos (Power, 2007; Maguire; Hardy, 2013). As organizações estão profundamente mergulhadas no risco: é inerente a elas a produção, avaliação e gerenciamento destes riscos (Hardy; Maguire, 2015).

Diversos são os conceitos sobre risco. Para March e Shapira (1987, p. 1404), "o risco é concebido comumente como uma reflexão da variação na distribuição de possíveis resultados, suas probabilidades, e seus valores subjetivos". Neste entendimento fica clara a ideia de que uma alternativa arriscada é aquela para a qual a variância é grande. Portanto, o risco é um dos atributos que, juntamente com o valor esperado de retorno de uma alternativa plausível, é utilizado no cálculo de apostas alternativas que possam ser empregadas (Pratt, 1964; Arrow, 1965).

Com uma visão distinta que desmembra a definição tradicional em dois elementos, Knight (1921) foi um dos precursores do conceito de risco. O autor afirma que, embora incerteza esteja inserida na definição familiar do risco, há diferenças entre os vocábulos que devem ser identificadas. Para Knight (1921) o risco é suscetível à quantificação e determinado estatisticamente quanto à probabilidade. A incerteza está enquadrada em casos em que não há a quantificação, e a probabilidade estatística cede lugar as probabilidades subjetivas. Em outras palavras, o risco estaria vinculado a situações e cenários estáveis que permitiriam uma 
previsão mais acurada, e a incerteza é associada a resultados imponderáveis.

Visão semelhante é proposta por Williamson (1985), na teoria econômica dos custos de transação ao associar incerteza à ambiguidade. O autor enfatiza que esta é produto da racionalidade limitada dos seres humanos em reunir todas as contingências possíveis a uma decisão. Entretanto, Galesne, Fensterseifer e Lamb (1999) debatem e sustentam que os termos, risco e incerteza, caminham concomitantemente. Para estes autores, o risco não existirá sem a presença da incerteza. Frequentemente na literatura sobre organizações os conceitos riscos e incerteza são tratados como sinônimos (Alvarez; Barney, 2005; Liesch; Welch; Buckley, 2011).

Os riscos e sua percepção foram abordados em pesquisas de naturezas distintas, no que tange ao gerenciamento deles na negociação financeira (Leaver; Reader, 2016), nos preditores da percepção do risco na mudança de clima e de preferências políticas organizacionais (Mumpower; Liu; Vedlitz, 2016), ou, até mesmo, a personalidade relacionada ao comportamento arriscado do condutor do veículo
Além disso, a determinação de um modo de entrada, por conter diferentes graus de comprometimento de recursos organizacionais (Sharma; Erramili, 2004) implicam em diferentes graus de risco. A negociação com os compradores também é uma situação preocupante, devido à ausência de garantias de pagamento (Mcdougall, 1989). Da mesma forma, outros aspectos da negociação como condições econômicas, preços e câmbio, geram riscos (Welch, Welch, 2004). As questões de porte e maturidade organizacional são, por vezes, gêneses de risco. Para Dib (2008) quanto menor a empresa, maior será sua flexibilidade e propensão ao enfrentamento de riscos internacionais. Mello, Rocha e Maculan (2009) afirmam que as empresas mais novas tendem a se arriscar mais no ambiente internacional.

Cavusgil, Knight e Riesenberger (2010) propõem uma classificação para os riscos em processos de internacionalização. As sete categorias identificadas comportam preocupações diversas e representam uma ampla gama de variáveis a serem monitoradas em uma gestão de risco no processo de internacionalização. O detalhamento das quatro categorias pode ser verificado na Tabela 1.

Tab. 1

Principais categorias e constructos de risco

\begin{tabular}{|c|c|}
\hline Categoria de Risco & Constructos que podem estar dentro da categoria \\
\hline Monetário & Exposição monetária; Avaliação de ativos; Tributação estrangeira; Preço inflacionário e de transferência. \\
\hline Comercial & $\begin{array}{l}\text { Problemas operacionais; Momentos de entrada; Intensidade competitiva; Estratégia mal implementada; } \\
\text { Parceiro fraco }\end{array}$ \\
\hline Intercultural & Diferenças culturais; Estilos de negociação; Estilos de processo decisório; Práticas éticas. \\
\hline Risco-país & $\begin{array}{l}\text { Intervenção governamental e protecionismo; Burocracia, entraves administrativos e corrupção; Legislação } \\
\text { desfavorável; Instabilidade social e política. }\end{array}$ \\
\hline
\end{tabular}

Fonte: Cavusgil, Knight e Riesenberger (2010)

(Chraif et al., 2016). Especificamente em relação aos processos de internacionalização o risco tem sido considerado um elemento central. Um exemplo disto é a afirmação de Bonaccorsi (1992, p. 627), ao apontar que na revisão da literatura está presente a "percepção de risco como construção chave para explicar o comportamento das exportações".

No processo de internacionalização, existem várias fontes de riscos que podem afetar a organização. A exploração das oportunidades, por si só, pode se tornar arriscada (Johanson; Vahlne, 2009), devido à eventualidade de os gestores tomarem decisões que não favoreçam a organização.
$\mathrm{Na}$ vertente comportamental de estudos sobre internacionalização há uma valorização do indivíduo e das redes de relacionamento na percepção e gestão de riscos. Para George et al. (2006) a percepção e a avaliação individual são os árbitros do significado e importância da informação sobre negócios estrangeiros, diferentes culturalmente e politicamente do país de origem. Outro indício é apontado por George, Wiklund e Zahra (2005), ao afirmarem que a percepção mais direcionada a detecção de riscos do que de oportunidades afeta negativamente o número de países e a extensão de atividades internacionais de uma organização. Assim, 
o que pode determinar se uma organização participará em operações internacionais e como o fará, é o risco envolvido no processo de internacionalização e como os gestores os percebem (Eduardsen; Marinova, 2016).

Por vezes, a explicação para tão diversas percepções, mesmo em situações externas comuns, encontram-se no background dos indivíduos, como, por exemplo, nas formas de experiência internacional (Maccrimmon; Wehrung, 1990). Tal visão é coerente com o proposto por March e Shapira (1987) ao afirmarem que as diferenças pessoais na percepção de incerteza e avaliações de risco realizadas pelos gestores afetam diretamente suas decisões, refletindo o impacto de sentimentos pessoais, experiência e contexto.

Evidências desta associação entre os elementos comportamentais e o risco em processos de internacionalização podem ser obtidas também na literatura sobre empreendedorismo internacional. Para Garud e Rappa (1994) a experiência pessoal e redes compostas por empresários e/ou tomadores de decisão auxiliam no entendimento do empreendedorismo internacional. Tanto para o indivíduo como para a empresa, sucessos e fracassos do passado, problemas encontrados, más experiências e similares, afetam o modo como qualquer nova atividade é vista. Questões de história na formação de percepções sobre a incerteza e nas avaliações de riscos, imersas em hábitos e maneiras de ver o mundo, fornecem o quadro de referência para a forma como as novas situações são avaliadas e ações adotadas (Garud; Rappa, 1994).

Ademais, a posição do gestor, quando analisado como elemento comportamental, pode influenciar em sua tomada de decisão. Organizações que são gerenciadas por proprietários se utilizam de decisões genéricas (heurísticas), apresentam mais vieses no momento de decisão, e recorrem a experiências passadas e critérios subjetivos, como a intuição, enquanto os gestores contratados apresentam padrões mais racionais (Shepherd; Williams; Patzelt, 2015).

A percepção dos indivíduos pode estar na base de sua propensão ou aversão aos riscos (Maccrimmon; Wehrung, 1990; Farmer, 1993; Fu, 1993). Portanto, em processos de internacionalização as percepções acerca do risco contribuem para o direcionamento e ritmo de expansão internacional, garantindo um rol de comportamentos possíveis de internacionalização, como exportações diretas, por trading company, ou joint venture (Liesch; Welch; Buckley, 2011; Eduardsen; MarinovA, 2016).

Os riscos podem ser encarados por uma ótica mais amena, e, desta maneira, percebidos como oportunidades (Gephart et al., 2009). Alinhado a este prisma, o gestor da organização deve reconhecer as plausíveis situações de riscos, antecipando-os e reunindo recursos para extrair a potencial vantagem da situação. Desta maneira, o risco que impactava negativamente a organização outrora, quando identificado e quantificado, passa a ser uma variável que possibilita auferir uma vantagem competitiva (Slywotzky; Drzik, 2007).

Em síntese é possível afirmar que os riscos são um elemento central nos processos de internacionalização e que a percepção dos envolvidos afeta a forma como a organização atuará internacionalmente. Desta forma a compreensão da origem das diferenças nas percepções de risco continua a ser uma área promissora de pesquisa (Janney; Dess, 2006) e pode auxiliar na compreensão do comportamento de internacionalização de organizações.

\section{METODOLOGIA}

A pesquisa realizada é calcada em uma ontologia nominalista (Burrel; Morgan, 1979) e é delineada como um estudo qualitativo. A metodologia escolhida foi o estudo de casos múltiplos, pois tal estratégia de investigação é compatível com o esforço de compreender melhor um fenômeno em seu contexto (Triviños, 1987).

Os critérios estabelecidos para a escolha dos casos foram: organizações pertencentes a um mesmo setor, concernentes as duas primeiras faixas de valores de exportação anual (acima de US\$ 50 milhões; e entre US\$ 10 milhões e US\$ 50 milhões) estabelecida pelo Ministério do Desenvolvimento, Indústria e Comércio Exterior (2015), e que estivessem entre as 25 exportadoras com maiores valores de exportação anual de seu município. Seguindo tais critérios que buscam cruzar os achados entre as três organizações, os casos escolhidos foram três empresas do setor alimentício com sedes nos municípios paranaenses de Medianeira e Foz do Iguaçu.

Considerando que a percepção do risco é inerente ao gestor, os entrevistados selecionados foram os gestores responsáveis pela exportação, com 
formações distintas: a gestora A (empresa Alfa) e o gestor B (empresa Beta) possuem pós-graduação, enquanto o gestor $G$ (empresa Gama) somente a graduação. As técnicas de coleta dos dados foram entrevistas, observação e análise documental. Foram realizadas, no mínimo, 3 entrevistas com o gestor de exportação de cada organização. O roteiro de entrevista foi composto com tópicos sobre a definição de risco; definição de incerteza; categorias de riscos comumente utilizadas para a análise dos processos de internacionalização; processo de análise dos países a se exportar; funcionamento do processo de exportação; contato e estudo acerca deste novo país; e o gerenciamento de riscos. As entrevistas duraram em média quarenta minutos, foram gravadas em áudio e transcritas em 89 páginas para a consecução da análise de conteúdo.

A observação foi realizada pelo período de 10 dias em cada organização. A partir da observação os pesquisadores puderam constituir diários de campos salientando os aspectos mais importantes para a compreensão de quais são os principais constructos de risco. Também foram disponibilizados pelas organizações documentos como pedidos, relatórios, dados do ranking do volume de exportações por país, bem como documentos que continham quedas ou ascensões mensais das exportações, dentre outros. A diversidade das formas de coleta favoreceu a triangulação dos dados e o aprofundamento do entendimento da organização estudada. A utilização de dados qualitativos coletados direta ou indiretamente podem, então, auxiliar na compreensão do fenômeno (De Freitas, 2011).

A análise de dados coletados seguiu os princípios da análise de conteúdo proposta por Bardin (1977). A definição das categorias seguiu o modelo fechado (Láville; Dionne, 1999), que consiste em o pesquisador decidir a priori as categorias apoiadas em um ponto de vista teórico. Para Bardin (1977) os dados qualitativos resultantes devem seguir três etapas na construção da análise: pré-análise, exploração do material, tratamento dos resultados e interpretação.

Na primeira etapa, foi organizado o banco de dados, colocados os dados de forma cronológica e algumas ideias iniciais foram sistematizadas. A segunda etapa iniciou-se com a codificação do material, seguindo as categorias já criadas. Transforma-se desta forma os dados brutos em unidades de análise. E, em última instância, a análise final dos dados mostrou-se como a etapa onde todo o conteúdo reunido foi trabalhado para responder a problemática de pesquisa. Visando a manutenção da confidencialidade, os nomes reais dos envolvidos e das organizações foram omitidos e representados pelos pseudônimos Alfa, Beta e Gama.

Quanto à validade do estudo, Stake (1995) aponta que a triangulação garante a precisão e as explicações referentes ao fenômeno estudado, e, por fim, aumenta a validade. Esta ainda foi buscada com uma descrição detalhada e rica do fenômeno. No que tange a confiabilidade, trabalhou-se com a triangulação e a reflexividade em vários momentos da pesquisa. Assim, a apresentação dos resultados e seus debates serão descritos detalhadamente na próxima seção.

\section{APRESENTAÇÃO E DISCUSSÃO DOS RESULTADOS}

Nesta seção serão apresentados os resultados de pesquisa e realizada a discussão com a literatura do campo de forma a embasar as conclusões do estudo. Como é característico dos estudos de caso múltiplos a grande quantidade de dados gerada foi organizada em função de temas, representadas pelos subitens desta seção:

- Caracterização das unidades sociais de análise;

- Descrição do processo de internacionalização;

- Conceitos de risco presentes nas unidades sociais de análise; e

- Relação entre as categorias de risco e as ações organizacionais.

\subsection{Caracterização das unidades sociais de análise}

As três empresas do setor alimentício selecionadas para este estudo possuem como canal do processo de internacionalização, a exportação regular a países definidos previamente. Visando contribuir para a compreensão dos casos estudados segue breve descrição das unidades sociais de análise.

A organização Alfa atua no setor frigorífico e está localizada no oeste do Estado do Paraná. Ela possui mais de nove mil membros e 31 unidades distribuídas no Paraná, Mato Grosso do Sul, Santa Catarina e Paraguai. Apesar de ter sido fundada há mais de 50 anos, somente no ano de 2001 se inseriu no mercado internacional. Suas exportações chegam a Europa, China, Chile, Japão, África do Sul, Arábia Saudita, Aruba, Canadá, Croácia, Cuba, Emirados Árabes e Líbano. A receita de suas exportações no ano de 2016 superou o valor de 50 milhões de dólares, tornandoa a maior exportadora, em critério de valor exportado 
anual, da cidade. Ademais, a organização faz exportação direta por meio do Porto de Paranaguá.

A empresa Beta opera na tríplice fronteira e está domiciliada no município de Foz do Iguaçu. Possuidora da natureza jurídica de sociedade por cotas de responsabilidade limitada exporta alimentos como balas, pirulitos e chicletes. Opera no cenário internacional desde 2007, exportando inicialmente para os países Paraguai e Argentina. Entretanto, em função da crise econômica Argentina e do default técnico ocorrido em meados de julho de 2014 após o calote do país em seus credores no ano de 2001, a organização suspendeu suas atividades com este país. Enquadrada como uma trade company, suas exportações saem do país pelo porto seco de Foz do Iguaçu. Atualmente exporta alimentos também de empresas parceiras, é a sétima maior exportadora de sua cidade (em critério de valor exportado anual), e sua receita anual está estimada entre um a dez milhões de dólares (MDIC, 2017).

A empresa Gama exporta seus produtos para o Paraguai. Deixou de atender somente o mercado interno em 1997, expandindo, assim, o conjunto de clientes. Presta serviços de exportação, bem como importação, sendo que o primeiro possui maior representatividade no conjunto das atividades desempenhadas, tornando-a especialista neste ramo. Com a internacionalização de alimentos, como óleos de sementes, garante a receita de vendas anual de um a dez milhões de dólares, ocupando a 240 posição das maiores exportadoras de sua cidade (em critério de valor exportado anual). Para suas exportações, utiliza o porto seco de Foz do Iguaçu.

\subsection{Elementos do processo de internacionalização}

Acerca do início das atividades de
internacionalização, os gestores das três organizações explanaram como foram desenvolvidas e implementadas as ações de pesquisa, análise e escolha dos países contemplados com seus produtos. $\mathrm{Na}$ percepção da gestora da Alfa, a principal motivação foi financeira. Assim, as decisões da empresa Alfa acerca da internacionalização de seus produtos foram pautadas no que revela o estudo de Malhotra, Sivakumar e Zhu (2009), isto é, na atratividade de grandes economias. Sendo assim, o Japão, a terceira maior economia do mundo (IPRI, 2017), foi o primeiro país a receber os produtos da Alfa. Anterior a exportação, a empresa Alfa recebeu uma habilitação específica do mercado japonês, juntamente com o Ministério da Agricultura, para, então, adentrar o território oriental. Além da motivação financeira, a gestora $A$ relatou que a organização recebeu um funcionário de parceira no Japão, com a finalidade de ensinar os funcionários locais a fazer a desossa e o cortes no padrão japonês. Este contato direto auxiliou na diminuição da distância psíquica por meio do conhecimento adquirido sobre o padrão e funcionamento desse mercado externo, o que leva a confirmação da proposição do estudo acerca da network organizacional de Nordman e Tolstoy (2014).

Com outra faceta de decisão, a empresa Beta optou por exportar para o Paraguai e Argentina devido a "proximidade geográfica e facilidade na comunicação", ou seja, a distância psíquica ser menor como fora discutido por Ambos e Hakanson (2014). O Paraguai, primeiro país a receber as exportações da organização, possui acesso direto por meio da Ponte da Amizade com a cidade de Foz do Iguaçu no Brasil, além das línguas maternas serem próximas, amenizando, portanto, a distância psíquica. O gestor B, que também é o sócio proprietário da organização, escolheu este destino inicial em virtude da "experiência comercial anterior a criação da empresa", alinhando-se as conclusões em relação ao background dos indivíduos que possuem efeito moderador sobre a percepção dos riscos, abordado por MacCrimmon e Wehrung (1990).

Seguindo os mesmos princípios que a empresa Beta, o gestor $G$ relatou como ocorreu à internacionalização na empresa Gama. Para ele, "não aproveitar a proximidade geográfica entre os países é uma miopia". Nesse sentido, a distância psíquica abordada por Johanson e Vahlne (1990), bem como por Ambos e Hakanson (2014), é menor quando se refere ao Brasil e Paraguai comparados a outros países, tanto culturalmente quanto a distância geográfica. Ademais, gestor $\mathrm{G}$, que também é o sócio proprietário da empresa, trabalhou anteriormente em outra exportadora que mantinha relações comerciais com o Paraguai, o que proporcionou aprendizagem sobre o referido país e foi utilizado para fundar a atual empresa Gama.

Frente aos dados é possível então afirmar que o processo de internacionalização e a escolha do mercado-alvo são afetados por condições objetivas como o tamanho da empresa e nível de recursos que ela dispõe para sobrepujar as adversidades impostas pela distância psíquica (Forsgren; Hagstrom; Peter, 2007). Assim como ocorreu no processo de 
internacionalização da empresa Alfa, as firmas maiores podem enfrentar as barreiras impostas pela distância psíquica em função de disponibilidade de maior base de recursos (Blomstermo; Sharma; Sallis, 2006). Por outro lado, o relato aponta para a relevância de fatores comportamentais, como a experiência internacional prévia do decisor, assim como proposto por MacCrimmon e Wehrung (1990).

\subsection{Conceitos e categorias de risco percebidos nas unidades sociais de análise}

Sob a ótica da gestora $A$, riscos são todos os acontecimentos internos e externos que comprometem de alguma forma o negócio da organização, interferindo no resultado projetado. Essa definição de risco, quando analisada, remete a definição realizada por March e Shapira (1987), apresentada no referencial teórico.

Para o gestor B os riscos são variáveis em que "há a possibilidade de algum domínio", onde a variabilidade resultante pode ser analisada e mensurada anteriormente a concretização desta influência. Seguindo, portanto, a lógica apresentada pelo teórico Knight (1921) acerca da distinção de risco e incerteza.

Contrapondo com outra vertente de definição, o gestor $G$ acredita que os riscos são incertezas referentes ao desempenho das atividades, bem como, em última instância, da organização, e ao que se planejou atingir. Comentou também que as incertezas podem ser originadas do mercado em que se atua. Entende, portanto, a relação de risco e incerteza como a apresentada por Galesne, Fensterseifer e Lamb (1999).

Como as definições de riscos para este conjunto de gestores remeteram diretamente ou indiretamente ao termo incerteza, pediu-se para cada um deles o que entendiam por incerteza ou situações incertas. As elucidações seguiram a lógica da definição de risco para cada gestor, e por meio da comparação com o referencial teórico, foi possível perceber similaridades entre as definições dos gestores e os autores da área.

Pondera a gestora $A$, que a incerteza é inerente ao ambiente instável que os cerca. A incerteza está presente nos planejamentos, a qual instaura lacunas nos cenários construídos, devido à dificuldade no mapeamento de todas as variáveis possíveis, bem como do seu impacto real nas atividades, ações e resultados organizacionais.
Ainda condizente com a conceituação de Knight (1921), o gestor B afirma que a incerteza está relacionada ao processo de decisão. No momento de tomada de decisão, existem variáveis que são conhecidas e outras variáveis que, por exemplo, dependem de outros atores organizacionais. Portanto, algumas situações que foram previstas possivelmente não irão efetivamente suceder, recorrendo, assim, a criação de cenários alinhados em uma ampla gama de incertezas. Como o gestor relata "as incertezas não são fatores previsíveis, muito menos seu impacto".

Persistindo na mesma linha da descrição a respeito de riscos, o gestor $\mathrm{G}$ declara que a incerteza e o risco estão muito atrelados. Para ele "são conceitos que não se pode desassociar e estão intimamente ligados". Assim, quando abordados, remetem um ao outro. A Tabela 2 sintetiza a relação observada entre a definição de risco e incerteza de cada gestor e a definição apresentada por teóricos da temática.

Tab. 2

Relação definição pessoal de risco e autores

\begin{tabular}{ll}
\hline Empresa & Autor \\
\hline Empresa Alfa & "Ameaça" - March e Shapira (1987) \\
Empresa Beta & "Mensurável" - Knight (1921) \\
Empresa Gama & "Incerteza" - Galesne, Fensterseifer e \\
& Lamb (1999) \\
\hline
\end{tabular}

Fonte: Autores (2017)

Ainda em relação aos riscos, quando questionados sobre a percepção da intensidade enfrentada nas operações empresariais, os gestores responsáveis pelo processo de internacionalização nas três organizações apontaram que o risco enfrentado no âmbito internacional está dentro de um parâmetro de normalidade. De acordo com o gestor G, "quem está na chuva é para se molhar".

Usando como parâmetro as categorias de risco apresentadas por Barreto (2004) e Neto (2004) é possivel perceber que as organizações percebem categorias distintas de risco. Na empresa Alfa, as categorias normalmente utilizadas para realizar avaliações são a de riscos monetários, riscos comerciais e risco-país, seja referente a entraves administrativos ou instabilidade social e política.

A avaliação dos riscos monetários está intimamente relacionada com a situação e funcionamento econômico do país almejado e as formas de entrada no processo de 
internacionalização. De acordo com a gestora A e confirmado pelos relatórios disponibilizados, mais de $90 \%$ da exportação é realizada de maneira direta, porém em situações que, por algum motivo, o cenário econômico do país alvo é instável, opta-se pelas trades, já que possuem a parte financeira mais sólida e o risco de não receber é menor.

O risco comercial está presente nas circunstâncias da apresentação e desenvolvimento da marca no comércio internacional. O modo de introdução, regular ou com oscilação, pode influir na percepção de sua marca pelo novo mercado, do mesmo modo que no mercado interno, que consome esses mesmos cortes além de alimentos empacotados, enlatados, vegetais congelados, conservas e massas.

Peculiar ao país que se atua, o risco-país se configura sobre o que é, ou não, permitido a entrada no país hospedeiro, apresentando como ônus a perda dos produtos. Ademais, riscos de instabilidade social e política (guerras) também estão presentes, salientando a importância de acompanhar cenários a fim de evitar maiores transtornos e prejuízos. Ainda segundo a gestora $A$, os dois últimos constructos de risco, isto é, risco de mercado e de guerra, são os mais eminentes. Portanto, adere-se, a cada exportação para um país novo em sua cartela, a uma medida de precaução. Procedimento relatado pela gestora e corroborado por meio das observações, antes de qualquer exportação um funcionário responsável pela empresa Alfa estuda o funcionamento do outro país, como o estilo de armazenagem e distribuição, além de monitoração constante da legislação desse comércio externo, do consumo, da produção interna daquele país, e de barreiras, caso venha a surgir alguma. Tenta-se ponderar ao máximo o risco em cada negócio a fim de evitar ou minimizá-lo.

Já para a empresa Beta as categorias de risco mais relevantes são as de riscos comerciais, constatados pelos documentos e observação das ações preventivas. Para o gestor $B$, as situações arriscadas mais problemáticas envolvem os erros, seja de quantidade, peso ou documental. Esses enganos, geralmente, incorrem em multas, além da possibilidade de perda da carga, dependendo do caso, onerando financeiramente a organização. Exemplos de tais falhas são, respectivamente, peso de carga a mais ou a menos, quantidades de produtos em excesso ou faltante, e descrição errônea do produto nos documentos. O risco-país nas operações da empresa Beta para a Argentina teve o seu ápice em julho do ano de 2014. No entanto, como a empresa decidiu suspender suas atividades para aquele país, salvo haja alteração no cenário, esse risco que trazia concomitantemente o risco financeiro, não se faz mais presente como uma ameaça constante, ao menos no que tange a operações para esta nação.

Já no caso da empresa Gama a categoria mais valorizada é a de risco monetário. Mesmo estando presente no mercado há vários anos, e investindo na manutenção de parcerias com seus clientes de longo período, o gestor não considera a organização isenta de, ocasionalmente, ter que lidar com o descumprimento de compromissos financeiros por parte dos seus clientes. Segundo o gestor $\mathrm{G}$ as razões típicas são endividamento demasiado de outras empresas para com Gama, ou por motivos de declaração de massa falida. Quanto a razões de má fé, há poucos casos registrados pela empresa Gama, decorrente da formação de parcerias longevas. A Tabela 3 apresenta um resumo das categorias de risco que são analisadas em cada organização.

Tab. 3

Principais categorias de risco analisadas

\begin{tabular}{ll}
\hline Empresa & Categorias \\
\hline Empresa Alfa & $\begin{array}{l}\text { Risco monetário, Risco comercial e Risco- } \\
\text { país }\end{array}$ \\
Empresa Beta & $\begin{array}{l}\text { Risco comercial, Risco-país } \\
\text { Empresa Gama }\end{array}$ \\
\hline
\end{tabular}

Fonte: Autores (2017)

A diversidade encontrada na conceituação do que é um risco e nas categorias percebidas de riscos no processo de internacionalização é coerente com o proposto por George et al. (2006). Ainda, como verificado na literatura por Shepherd, Williams e Patzelt (2015), pode-se inferir que existe uma diferença na percepção e decisão de gestores proprietários e gestores profissionais contratados. É plausível ponderar que os gestores proprietários tomam decisões baseados em elementos subjetivos, frequentemente suportadas por percepções e experiências pessoais. Já em organizações com profissionais, como na empresa Alfa, há um maior desenvolvimento de processos burocrático-racionais que enfatizam os riscos mensuráveis, além de uma tomada de decisão voltada a ótica econômicofinanceira, a qual é fundamentada na classificação de probabilidade e rentabilidade potencial. Nos casos estudados fica evidenciado que a percepção e a avaliação individual afetam a forma como são 
interpretadas as informações e categorizados os riscos em operações internacionais.

\subsection{Relação entre as categorias de risco e as ações organizacionais}

Em relação às ações organizacionais promovidas para prevenir e minimizar a ocorrência de riscos, foi observado e corroborado por meio de relatórios, que a empresa Alfa, antes de se inserir em um novo mercado, realiza uma avaliação de quais produtos similares estão disponíveis para a exportação e quais são consumidos no país-alvo. Da mesma forma, o setor do controle de qualidade se encarrega de verificar a habilitação necessária a atividade internacional, bem como comprovar se o estatuto da empresa Alfa se ajusta a legislação do país designado, disponibilizar os laudos e oferecer um croqui da embalagem, para que, ao final se tenham os elementos necessários para a negociação com o parceiro em potencial. Além do estudo inicial sobre seminários e cursos especializados aos despachantes.

Na empresa Gama, a gestão de riscos se pauta no acompanhamento dos cenários econômicos internacionais, isto é, na verificação se a produção interna está crescendo e a demanda por produtos exportados diminuindo. Outro exemplo é a análise se o volume comprado pelo parceiro está baixando no período, o que pode ser um alerta para a atual situação financeira deste.

Comum as três empresas, há uma relação entre a concepção de risco e as ações organizacionais. A gestão de risco das empresas está pautada na percepção de quais seriam os riscos que ameaçam o funcionamento da organização pelo gestor. Portanto, a percepção e compreensão individual dos riscos podem, como teorizado por March e Shapira (1987), afetar as decisões organizacionais. A Tabela 4 sumariza esse nexo entre os riscos analisados e ações desempenhadas.

Tab. 4

Riscos analisados e as ações organizacionais

\begin{tabular}{lll}
\hline Empresa & Categoria de Risco & Ações organizacionais \\
\hline Alfa & $\begin{array}{l}\text { Risco monetário, Risco } \\
\text { comercial e Risco-país }\end{array}$ & $\begin{array}{l}\text { Ademais do estudo completo sobre as características do país almejado, na } \\
\text { empresa Alfa há o acompanhamento de todo o processo, incluindo da } \\
\text { documentação e da localização diária do container refrigerado que transporta os } \\
\text { produtos. }\end{array}$ \\
\hline Beta & Risco comercial, Risco-país & $\begin{array}{l}\text { Além de se monitorar os riscos propriamente ditos, a organização oferece } \\
\text { seminários e cursos especializados aos despachantes, para, assim, minimizar os } \\
\text { riscos de falhas documentais. }\end{array}$ \\
\hline Gama & Risco monetário & $\begin{array}{l}\text { Acompanhamento dos cenários econômicos internacionais, isto é, se verifica se a } \\
\text { produção interna está crescendo e a demanda por produtos exportados } \\
\text { diminuindo, por exemplo, e se o volume comprado pelo parceiro está baixando } \\
\text { no período, o que pode ser um alerta para a atual situação financeira deste. }\end{array}$
\end{tabular}

Fonte: Autores (2017)

as características do país almejado, na empresa Alfa há o acompanhamento de todo o processo, incluindo a documentação e a localização diária do container refrigerado que transporta os produtos.

Com uma lente voltada para o operacional, após estudos sobre o funcionamento das barreiras tributárias e legislação do país almejado, a avaliação do risco na empresa Beta torna-se mais palpável e com níveis aceitáveis. No entanto, o risco documental ainda persiste, especialmente em questões relacionadas ao enquadramento de produtos, e pode resultar em problemas de portos e implicações financeiras. Visando minimizar a possibilidade de falhas documentais na empresa Beta, são oferecidos
Para cada categoria de risco percebida na organização, há ações organizacionais estratégicas que buscam minimizar o risco. Esta relação encontrada é coerente com o proposto pela teoria comportamental de internacionalização e aponta que a compreensão do conceito e categorias de risco percebidas tem impacto no processo de internacionalização e podem ser um caminho para a compreensão do comportamento de exportação.

\section{CONCLUSÕES}

O processo de internacionalização é uma prática cada vez mais difundida no Brasil e implica em um recrudescimento dos riscos experimentados pelas organizações. Para compreender os conceitos e 
categorias de risco associados ao processo de internacionalização presentes nas três organizações estudadas, foi desenvolvido um estudo de casos múltiplos, com coleta de informações por meio de entrevistas com os gestores de exportação, observação e análise documental.

A análise da percepção dos gestores de exportação sobre o processo de internacionalização indicou uma coerência com a produção teórica da escola de Uppsala, que prevê que a maior distância psíquica com o mercado-alvo implica em menor atratividade deste e maior dependência dos recursos organizacionais. Nas empresas estudadas somente a de maior porte e recursos buscou um mercado com maior distância psíquica; as menores investiram na relação com países de maior proximidade psíquica.

Sobre a concepção de risco, os gestores entrevistados se referiram a conceitos e categorias distintas. Apesar de todos considerarem a dimensão risco financeiro, nos casos analisados diferentes categorias de risco foram valorizadas. As categorias descritas são relacionadas às peculiaridades de cada organização. A fim de eliminar ou minimizar estes riscos, as empresas disseminam e fomentam uma gestão de riscos pautada na análise e controle das operações organizacionais, assim como dos cenários mundiais. Foram encontradas evidências de uma coerência entre a categoria de risco percebida e as ações organizacionais de prevenção.

Uma contribuição dos resultados desta pesquisa são as evidências que reforçam a relevância do modelo comportamental para a análise e compreensão de processos de internacionalização. Os resultados indicam que as construções cognitivas dos envolvidos nas práticas organizacionais são uma dimensão relevante para promover maior compreensão do processo de internacionalização. Outra contribuição é que os resultados encontrados reforçam a necessidade de investimentos organizacionais na capacitação e ampliação do repertório de experiência dos decisores envolvidos em internacionalização. Como sua percepção e organização das informações em relação ao risco afetam as práticas organizacionais, gestores com escopo reduzido de percepção em relação ao tema podem conduzir ações ineficazes.

Com relação à indicação de pesquisas futuras, recomenda-se verificar a relação do uso de determinadas categorias de riscos e a escolha de países clientes. Investigações que levem em conta a racionalidade limitada dos indivíduos e as formas como a cognição dos envolvidos afeta e é afetada pelas práticas organizacionais poderiam contribuir para uma maior compreensão dos riscos em processos de internacionalização.

\section{REFERÊNCIAS}

- ANDRESEN, M.; BERGDOLT, F. A systematic literature review on the definitions of global mindset and cultural intelligence: merging two different research streams. The International Journal of Human Resource Management, v. 28, n.1, 2017.

- BANDEIRA-DE-MELLO, R.; FLEURY, M.T.L.; AVELINE, C. E. S.; GAMA, M. A. B. Unpacking the ambidesterity implementation process in the internationalization of emerging market multinationals. Journal of Business Research, v. 1, p. 1-13, 2016.

- BEECHLER, S.; JAVIDAN, M. Leading with a global mindset: The Global Mindset. Advances in International Management, v. 19, p.131-169, 2007.

- $\quad$ BLACK, J. S. The relationship of personal characteristics with the adjustment of Japanese expatriate managers. Management International Review, v.30, n.2, p.119-134, 1990

- BlOMStermo, A.; ShARMA, D. D. Learning in the internationalisation process off firms. Edward Elgar Publishing, 2003.

- BORINI, F.; FLEURY, M. Development of non-local competences in foreign subsidiaries of Brazilian multinationals. European Business Review, v.23, i.1, p.106-119, 2011. DOI: 0.1108/09555341111098017

- BOUQUET, C. Building global mindsets: an attentionbased perspective. New York: Palgrave Macmillan, 2005.

- BROWN, J. F. O executivo global: conselhos práticos para o sucesso em um mercado transcultural. Porto Alegre: Bookman, 2008.

- Calderón, P. A. L.; guedes, A. L. M.; CARVAlho, R. W. Gestão internacional de recursos humanos: adaptabilidade intercultura na expatriação de brasileiros. Internext - São Paulo, v.11, n. 1, p. 6-20, mai./ago. 2016.

- DEKKER, W. D.; JANSEN, P. G. W. and VINKENBURG, C. J. Dimensions of an individual global mindset, 2005.

- $\quad$ EGEL, E.; FRY, L.W. Cultivating a Global Mindset Through "Being-Centered" leadership. In: Judi Neal. Handbook of Personal and Organizational Transformation. USA: Springer International Publishing, 2017.

- FELÍCIO, J.; CALDEIRINHA, V.; RODRIGUES, R. Global mindset and the internalization of small firms: the importance of the characteristics of entrepreneurs. International Entrepreneurship and Management Journal, v. 8, n.4, p. 467-485, 2012.

- Fleury, M.T.L.; Fleury, A. O desenvolvimento das multinacionais brasileiras no cenário global. GVExecutivo, v. 15, n. 1, jan./jun. 2016. 
- FleUry, A. ; SHI, Y.; FERREIRA JR., S.; CORDEIRO, J.H.; FLEURY, M.T.L. O desenvolvimento de competências de multinacionais brasileiras. GV Pesquisa, anuário de pesquisa 2015-2016.

- GHEMAWAT, P. Redefining global strategy: crossing borders in a world where differences still matter. Harvard Business School Press, 2007.

- GUPTA, A.; GOVINDARAJAN, V. Cultivating a global mindset. Academy of Management Executive, v.16, n.1, p.116-126, 2002.

- HITT, M. A.; IRELAND, D.; CAMP, S. M.; SEXTON, D. L. Guest editors'introuction to the special issue strategic entrepreuneurship: entrepreneurial strategies for wealth creation. Strategic Management Journal, v. 22, n.6/7, p. 479-491, 2001.

- HOUSE, R.; JAVIDAN, M.; DORFMAN, P. Project GLOBE: An Introduction. Applied Psychology: An International Review, v. 50, n.4, p. 489-505, 2001.

- JAVIDAN, M.; STAHL, G. K.; BRODBECK, F.; WILDERO, C. P.M. Cross-border transfer of knowledge: cultural lessons from Project GLOBE. Academy of Management Executive, v. 19, n.2, 2005

- JAVIDAN, M.; STEERS, R. M.; HITT, M. A. The global mindset: advances in international management. Oxford: Elsevier JAl, 2007.

- JAVIDAN, M.; BOWEN, D. The 'Global Mindset' of managers: What it is, why it matters, and how to develop it. Organizational Dynamics, v. 42, n. 2, p. 145155, 2013.

- JAVIDAN, M.; WALKER, J. L. Developing your global mindset: the handbook for successful global leaders. Edina: Beaver's Pond, 2013.

- JEANNET, J. P. Managing with a global mindset. London: Times/Prentice Hall, 2000.

- KEDIA, B.; MUKHERJI, A. Global managers: developing a mindset for global competitiveness. Journal of World Business, v.34, n.3, p. 230-252, 1999.

- KEFALAS, A. G. Think globally, act locally. Thunderbird International Business Review, v.40, n.6, p.547-562, 1998.

- KUADA, J. Global mindsets: exploration and perspectivas. USA: Routkedge, 2016.

- LEE, S. M.; PETERSON, S. N. Culture, entrepreneurial orientation, and global competitiveness. Journal of World Business, v. 35, p. 401-416, 2000.

- McCAll, M.; HOLLENBECK, G. Developing global executives: the lessons of international experience. Boston: Harvard Business School Press, 2002.

- MIOCEVIC, D.; CRNJAK-KARANOVIC, B. Global mindset: a cognitive driver of small and medium-sized enterprise internationalization; The case of Croatian exporters. EuroMed Journal of Business, v. 7, n.2, p. 142-160, 2012.
- NEVES, V.; TOMEI, P. Global mindset e comportamento da liderança. Revista Ibero-Americana de Estratégia RIAE, v. 15, n.2. April/June. 2016.

- OSLAND, J. S., BIRD, A., MENDENHALL, M.; OSLAND, A. Developing global leadership capabilities and global mindset: a review. In: STAHL, G. K. and BJÖRKMAN, I. Handbook of Research in International Human Resource Management, 2. ed. Reino Unido: Edward Elgar Publishing, 2012.

- Plummer, D. L. Overview of the Field of diversity management. In: __. Handbook of Diversity Management: beyond awareness to competency based learning. Laham: University Press of America. 2001. Cap. 5.

- $\quad$ RAMSEY, J. R.; RUTTI, R. M.; LORENZ, M. P.; BARAKAT, L, L.; SANT'ANNA, A.S. Developing global transformational leaders. Journal of World Business, v. 52, i. 4, p. 461-473, June 2017. https://doi.org/10.1016/j.jwb.2016.06.002

- REIS, G. G.; FLEURY, M. T. L. O global mindset de empresas early movers e late movers é diferente? Influências do ambiente local e do grau de internacionalização. XIII Semead na FEA-USP, Anais Semead... 2010.

- ROSAL, A.S.R. Gestão de Recursos Humanos Internacional e o Ajustamento Intercultural do Executivo Expatriado. Psic. Rev. São Paulo, v. 24, n.1, p. 121-141, 2015.

- RUAS, R. Desenvolvimento de competências gerenciais e a contribuição da aprendizagem organizacional. In FLEURY, M. T.; OLIVEIRA Jr., M (Org.). Gestão estratégica do conhecimento. São Paulo: Atlas, 2001. p.242-267.

- SANDBERG, J.; TARGAMA, A. The rise of an interpretative perspective on management. Managing Understanding in Organizations. California: Sage, 2007.

- StORY, J. S. P.; BARBUto, J. E. Global Mindset: A Construct Clarification and Framework. Journal of Leadership \& Organizational Studies, v. 18, n. 3, p. 377384, 2011.

- StORY, J. S. P., BARBUtO JR., J. E., LUTHANS, F.; BOVAIRD, J. A. Meeting the challenges of effective international HRM: analysis of the antecedents of global mindset. Human Resource Management, v. 53, n.1, p. 131-155, 2014.

- TANURE, B.; DUARTE, R. G. Sensibilidade cultural. GV Executivo, v.5, n.4, 2006.

- tanure, B., Cyrino, A.; Penido, E. Seus executivos estão prontos para comandar lá fora? Valor Econômico - Eu e Carreira, São Paulo, 2005.

- uRban, T. P.; Fleury, M. T. L. Competências e internacionalização: um estudo de caso em empresa brasileira com subsidiária de produção no exterior. VIII Semead na FEA-USP, 2005.

- WEICK, K. E.; SUTCLIFFE K.M.; OBSTFELD, D. Organizing and the process of sensemaking. Organization Science, v.16, n.4, p.409-421, 2005. 
- WINCK, M.F.; FROEHLICH, C.; BOHNENBERGER, M. C.; BESSI, V. G.; SCHREIBER, D. O desenvolvimento das competências e líderes globais: uma abordagem baseada nos estudos de global mindset leadership. Internext - São Paulo, v.11, n. 2, p. 35-48, mai./ago. 2016.

\section{SOBRE OS AUTORES}

- Gabrielle Ribeiro Rodrigues da Silva é Doutoranda em Administração pela Universidade Federal do Paraná (PPGADM/UFPR) na linha de pesquisa Estratégia e Análise Organizacional (EAO) como bolsista da Coordenação de Aperfeiçoamento de Pessoal de Nível Superior (CAPES), mestra em Administração pela Universidade Federal do Paraná (PPGADM/UFPR) na linha de pesquisa de Estratégia e Análise Organizacional como bolsista do Conselho Nacional de Desenvolvimento Científico e Tecnológico (CNPq) e Bacharel em Administração pela Universidade Estadual do Oeste do Paraná (Unioeste). Os principais interesses de pesquisa estão relacionados a temáticas como o risco, percepção de risco, gestão de risco, internacionalização e processo decisório. E-mail: gabii.ribeiiro@hotmail.com ORCID: $h t t p: / / o r c i d . o r g / 0000-0001-6638-130 X$

- Simone Cristina Ramos possui graduação em Psicologia pela Universidade Federal do Paraná (1997), especialização em Gestão de Pessoas pela UFPR (2001), especialização em administração pela PUCPR (2003), mestrado em Administração pela Pontifícia Universidade Católica do Paraná (2005) e doutorado em Administração pela UFPR (2015). É professora Adjunta da UFPR - Universidade Federal do Paraná na graduação e especialização. Tem experiência na área de Administração, com ênfase em Gestão de Pessoas e Estratégia, atuando principalmente nos seguintes temas: empreendedorismo, processo decisório, cognição, gestão de pessoas, ensino de administração. E-mail: simone.crisr@gmail.com ORCID: http://orcid.org/0000-0001-9460-6481

- Gustavo Abib possui graduação em Administração de Empresas pela Universidade Estadual de Londrina (1999), mestrado em Administração pela Universidade Federal do Paraná (2006) e Doutorado em Administração pela Universidade Federal do Rio Grande do Sul(2011). É professor adjunto da UFPR e atua em cursos de graduação e pós graduação, com ampla experiência na área de Administração, com ênfase em Sistemas de Informações, Planejamento Estratégico e Recursos Humanos. E-mail: gustavo.abib@gmail.com ORCID: http://orcid.org/0000-0002-8768-9669

- Karina De Déa Roglio é Doutora em Engenharia de Produção pela Universidade Federal de Santa Catarina (2006). Visiting Scholar na Northwestern University - Kellogg School of Management (20032004). Mestre em Engenharia de Produção pela Universidade Federal de Santa Catarina (1998). Especialista em Administração de Recursos Humanos pela Universidade Federal de Santa Catarina (1993). Administradora pela Universidade do Estado de Santa Catarina (1990). Professora adjunta da Universidade Federal do Paraná (UFPR). Autora de artigos na área de Process Decisorio, Desenvolvimento de Executivos e Gestão de Pessoas, publicados em periódicos nacionais e internacionais. Membro da Academy of Management desde 2006 e da Society for Organizational Learning desde 2001. Áreas de interesse: Processo Decisório Estratégico. Processo Decisório de Demissão. Processo Decisório na area de Gestão de Pessoas. Processo Reflexivo de Gestores. E-mail: karinaroglio@gmail.com ORCID: http://orcid.org/0000-0002-5256-8330. 


\section{Risk perception in the internationalization of the food sector}

Gabrielle Ribeiro Rodrigues da Silva, Simone Cristina Ramos,

Gustavo Abib, and Karina De Déa Roglio

Federal University of Paraná, UFPR, Curitiba, PR, Brazil

\begin{tabular}{l}
\hline ARTICLE DETAILS \\
\hline Article history: \\
Received: 18 may 2017 \\
Reviewed: 11 September 2017 \\
Reviewed: 15 December de 2017 \\
Accepted: 22 February 2018 \\
Available online: 01 May 2018 \\
"Double blind review" System \\
Scientific Editor \\
Ilan Avrichir
\end{tabular}

\section{Keywords:}

Risk

Internationalization

Behavior Theory of Internationalization

Risk Perception

\begin{abstract}
The internationalization process of Brazilian organizations is gradually progressing. In international activities, the risk present in the domestic market increases due to the particular characteristics of the market in which the organization desires to introduce a product or service. Although under normal conditions it could said that it is necessary to analyze all the risks that could affect the organization, bounded rationality does not allow the manager to process all the information, be it through lack of knowledge or analytical capacity. Thus, the aim of this article is to understand the perceived risks associated with the internationalization of companies in the food sector. The guiding approach is a multiple case study, with semi-structured interviews, observation and document analysis. The results show diversity among organizations with regard to the concept of risk, differences between the kinds of risks considered and the influence of this perception on organizational practices. The contributions of the study include the construction of evidence coherent with the behavior theory of internationalization, which is more than a commercial and economic process, constituting a complex construction of reality influenced by the perception and attitudes of the managers involved.
\end{abstract}

(C) 2018 Internext | ESPM. All rights reserved!

Para citar este artigo:

Silva, G. R. R., Ramos, S. C., Abib, G. e Roglio, K. D. D. (2018) Percepção de riscos na internacionalização do setor alimentício. Internext - Revista Eletrônica de Negócios Internacionais, 13 (2), 01-13. DOI: http://dx.doi.org/ 10.18568/1980-4865.1321-13

Para acessar este artigo: http://dx.doi.org/ 10.18568/1980-4865.1321-13 